\title{
ENTRE MOURAS ENCANTADAS E ENCANTADOS DA AMAZÔNIA: UMA ABORDAGEM DECOLONIAL
}

\section{BETWEEN AMAZON'S ENCHANTED AND ENCHANTED MOORS: A DECOLONIAL APPROACH}

\author{
Mara Genecy Centeno Nogueira ${ }^{1}$ \\ Sonia Maria Gomes Sampaio ${ }^{2}$
}

\begin{abstract}
RESUMO: O objetivo deste artigo é analisar como agiu o colonizador ibérico quando chegou ao Novo Mundo e se deparou com povos nativos de culturas muito diversas e como ignorou totalmente os costumes e tentou invisibilizar o outro. Além do mais, o texto em questão visa discutir e examinar como elementos da cultura popular portuguesa foram infiltrados e ressignificados no Brasil e como os "restos ou rejeitados" fizeram para manter viva a sua base cultural. Para fazermos tal percurso apresentaremos a lenda da Moura Encantada e a da Moura Torta, ambas europeias, e as analisaremos tendo como contraponto as narrativas de mitos indígenas, dentre eles o da Iara, de forma a demonstrar que o caldeirão cultural não foi e não é uma via de mão única e que muitos de nossos personagens mitológicos encontrados, principalmente, nas florestas do Brasil e de outros países da América do Sul, renderam histórias e aguçaram o imaginário europeu, especialmente, sobre a Amazônia e tudo que nela pode ser reinventado. Para referendar nossas análises nos valeremos dos autores Walter Mignollo, Aníbal Quijano, Edgardo Lander e Frantz Fanon.
\end{abstract}

PALAVRAS-CHAVE: Amazônia; Colonizador; Moura Encantada; Moura Torta; Iara; Encantados.

\begin{abstract}
In this article we aim to analyze how the Iberian colonists behaved when they arrived in the New World and encountered native peoples of diverse cultures as well as how the colonizers completely ignored the native customs and traditions, making the "other" invisible. Furthermore, we propose to discuss and examine how the elements of the Portuguese popular culture were infiltrated and re-signified into Brazil, to understand how the "remains or rejected" were able to keep their cultural base alive. In order to go through such study, we will present the European legends of the Enchanted Moorish and the Crooked Moorish, which will be analyzed in comparison with the narratives of Indigenous myths, amongst them the myth of the Iara. We intend to demonstrate that the cultural melting pot was not and is not a one-way road but also that many of our mythological characters, found primarily in the forests of Brazil and other South American countries, rendered stories and sharpened the European imagination regarding the Amazon and all that can be reinvented in it. Decolonial thinkers such as Walter Mignolo, Aníbal Quijano, Frantz Fanon, Edgardo Lander, among others, will support our study.
\end{abstract}

KEYWORDS: Amazon; Colonist; Enchanted Moorish; Crooked Moorish; Iara; Enchanted.

\footnotetext{
${ }^{1}$ Universidade Federal de Rondônia - UNIR, Departamento de História, Programa de Mestrado Acadêmico em Estudos Literários, Porto Velho, Rondônia, Brasil; https://orcid.org/0000-0003-0660-2128; maracenteno@gmail.com

${ }^{2}$ Universidade Federal de Rondônia - UNIR, Departamento de Línguas Vernáculas, Programas de Mestrados Acadêmicos em Letras e Estudos Literários, Porto Velho, Rondônia, Brasil; https://orcid.org/0000-0003-44664397 ; soniagomesampaio@gmail.com
}

Rev. Bras. Lit. Comp. Niterói, v. 22, n. 39, pp. 77-84, jan. /abr. 2020 https://doi.org/10.1590/2596-304X20202239mgcn 
Tudo aquilo que a nossa civilização rejeita, pisa e mija em cima, serve para poesia

[...] As coisas jogadas fora têm grande importância como um homem jogado fora.

(Manoel de Barros, 2001, p. 15)

O "encontro" entre o Velho e o Novo Mundo, Europa e América, revelou o diferente aos colonizadores ibéricos ${ }^{3}$, porém os aventureiros míopes e teleguiados pelas lentes do processo colonizador rejeitaram, maiormente, as diferentes culturas das civilizações da América. Pisaram, mijaram, humilharam, escravizaram, sangraram e dizimaram sociedades indígenas jogando-as fora como se fossem lixo, tal como anunciara Frantz Fanon em sua obra Peles negras, máscaras brancas (2008) afirmando que no processo de colonização demoniza-se o diferente, o outro, tratando-o como um membro assustador, e superestima-se o branco europeu. Assim, os colonizadores ao efetuarem essa prática esqueceram que estavam em um planeta e como tal esse é fechado, portanto, tudo que jogamos pretensamente fora, acaba dentro. E no caso da América, o anunciado novo mundo, homens e mulheres perceberam isso e se mostraram dentro, ao desencadearem lutas pela manutenção de suas bases culturais, e, ao invés de perderem a esperança, continuaram a extrair poesia da natureza e das coisas simples da vida. Afinal, como infere o poema de Manoel Barros, tudo o que é rejeitado pode ser utilizado como matéria de poesia.

Os canais simbólicos que foram se construindo após o momento do "encontro" entre esses dois mundos tenderam sempre a privilegiar a cultura do colonizador ibérico, porém temos que chamar a atenção para o processo de colonização e analisar as condições históricas em que se deu o que podemos denominar de "nascimento cultural" do Novo Mundo.

Em princípio, como registrou a historiografia, até os anos 80, no Brasil, era decretada, via Europa e suas produções discursivas, a inexistência das bases culturais dos nativos e as análises levavam o leitor a receber, de forma filtrada, somente as bases da cultura eurocêntrica. No dizer de Enrique Dussel (1993, p. 8) a ideia de Europa compara-se a de "um 'ego' descobridor, conquistador, colonizador da Alteridade constitutiva da própria modernidade". Nesse sentido a América foi encoberta em seus valores e produções para que a Europa continuasse a ser a grande referência de ciência, arte, cultura e comportamento.

Vale esclarecer que ao recorrermos ao termo nativo, estamos utilizando a concepção de nativo apresentada por Eduardo Viveiros de Castro em seu artigo $O$ nativo relativo (2002), quando assevera que nativo não é necessariamente e tão somente um selvagem ou nascido no local, na região, mas aqueles que vindos de outros lugares incorporam o local e os costumes como seus, aceitando e fazendo parte do universo cultural em questão.

Entretanto, nas últimas décadas do presente século, o que se verificou, muito satisfatoriamente, foi a construção de um cabedal teórico procedente de pesquisadores como Aníbal Quijano, Enrique Dussel, Walter Mignolo, Edgardo Lander, dentre outros, que buscam em seus trabalhos apresentar e repensar a História da América em um contexto Decolonial, ou seja, descortinando as fronteiras do dito "Sistema Colonial" em seu caráter homogeneizador. Vale dizer que parte dos referidos autores que se propuseram a repensar a História da América

\footnotetext{
${ }^{3}$ Utilizaremos o termo "colonizadores ibéricos" para demarcamos de quem estamos falando, ou seja, portugueses e espanhóis. Comumente observamos que quando se trata de textos sobre a América a maior parte dos estudiosos se refere ao europeu para designar o colonizador, porém esse termo assim como a expressão "índio" continua a representar os reflexos de uma tradição intelectual que determinou uma categoria de análise que não evidencia singularidades ou a soma dos traços particulares que os identificam, pois o ideal é que fossem chamados por suas etnias. Devemos lembrar que tanto o índio como o colonizador são construções do projeto colonizador que insere tanto um quanto o outro em categorias de forma a classificá-los e a demarcar territórios.
} 
fizeram também uma incursão, com ênfase, pela América Latina, desconstruindo a visão de que essa América era tão somente uma extensão vulgar e maltrapilha da Europa.

Assim, buscamos discutir, problematizar e interrogar as experiências locais procurando retirar o véu que ainda nos encobre e demonstrar os perigos de uma histórica única para a qual nos alerta a escritora nigeriana Chimamanda Adichie, que discorreu sobre o tema em uma Conferência realizada em 2009 nos Estados Unidos.

$\mathrm{Na}$ esteira desses acontecimentos, o presente texto visa colocar em discussão como elementos da cultura popular portuguesa foram infiltrados e ressignificados no Brasil e como os "restos ou os rejeitados" fizeram para manter vivas as suas bases culturais. Para fazermos tal percurso, iremos apresentar e analisar a lenda da Moura Encantada e a da Moura Torta, ambas europeias, tendo em contraponto as narrativas de mitos indígenas, mais pontualmente a da Iara, de forma a demonstrar que o caldeirão cultural não foi e não é uma via de mão única, uma vez que muitos de nossos personagens mitológicos renderam histórias e aguçaram o imaginário europeu, principalmente, nas terras distantes da Amazônia.

\section{Das Mouras Encantadas e Tortas aos Encantados da Amazônia}

$\mathrm{Na}$ chegada a este continente, ainda sem a denominação de América, o colonizador ibérico se deparou com tipos humanos e bases culturais completamente diferentes das que conhecia e experienciava na Europa. Embalado pela cobiça, pela possibilidade de expansão comercial e, maximamente, visando sair da crise do final do período medieval, lançou-se ao mar em busca de novos territórios, metais preciosos, mão de obra barata, preferencialmente escrava, e tudo que pudesse transformar em lucro. Todo esse conjunto de expectativas acabou desenhando um cenário que no dizer de Bosi (1992, p. 21) "brutaliza e faz retroceder às formas cruentas o cotidiano vivido pelos dominados".

Valendo-se de discursos "civilizatórios", os colonizadores ibéricos, ao chegarem à outra margem do Ocidente e se depararem com homens completamente diferentes e com traços culturais diversos dos seus, passaram a classificar os nativos e a impor códigos ordenadores como forma de retirá-los da barbárie e, consequentemente, do estágio que o colonizador definia como sendo de letargia, uma vez que viviam sem lei, sem fé e sem rei, como infere o cronista,

Quando em 1570 o cronista Pero de Magalhães Gândavo defende a colonização do Brasil por portugueses empobrecidos, imputa aos indígenas traços negativos adicionais. Acrescenta Gândavo que "a língua deste gentio [...] carece de três letras, não se acha nella $\mathrm{F}$, nem L, nem R, cousa digna de espanto, porque assi não têm Fé, nem Lei, nem Rei; e desta maneira vivem sem justiça e desordenadamente (Giucci, 1993, p. 306).

O mundo que os colonizadores queriam construir na América era baseado em suas experiências, sendo a Europa a referência. Essa construção não se deu sem confrontos, ou seja, não foi possível apagar e reescrever a história da América para construir um novo gênesis. Os resultados do encontro foram grandes massacres promovidos nas regiões das várias amazônias da América do Sul, e o extermínio de diversas etnias. Portanto, importava seguir o projeto colonizador.

É possível supor que a partir desses fatos esteja ancorada uma das vertentes da lógica que os colonizadores ibéricos construíram em relação ao "Outro": não queriam descobri-lo de forma a aprender novas culturas, novos modos de fazer e viver. Assim, encobri-lo foi o caminho mais fácil. Tornar o Novo Mundo civilizado implicava em demarcar o lugar dos sujeitos que deveriam ser assujeitados, não só em relação aos seus corpos, mas também em sua cultura e sua língua.

Rev. Bras. Lit. Comp. Niterói, v. 22, n. 39, pp. 77-84, jan. /abr. 2020 
Observamos com isso o que Dussel (1993) denominou da invenção do "ser asiático", ao se referir ao engano promovido pelo genovês Cristóvão Colombo quando partiu de Huelva, na Espanha, e acreditava ter chegado a Ásia e não a América. Logo, o nativo nesse contexto é encoberto e negado, uma vez que a ele não é dado o direito de garantir a sua identidade, ao contrário do colonizador ibérico e de todos os outros colonizadores, que na condição de homens modernos trazem a prerrogativa de serem ativos e, portanto, legitimados a dominar e a negar povos.

Foi justamente nesse "encontro" entre os dois mundos que comunidades indígenas desapareceram e traços culturais foram apagados para acentuar ainda mais a classificação dos diferentes e para demonstrar quem mandava. E no dizer de Aníbal Quijano (2010, p. 120) foi a partir da classificação imposta à América que populações de todo mundo começaram a ser classificadas "em identidades 'raciais' divididas entre os dominantes/superiores 'europeus' e os dominados/inferiores 'não-europeus"”.

Desse "encontro", podemos balizar que nasceram desencontros e/ou confrontos. Nem todos os indígenas foram "bons selvagens", ou seja, deixaram-se colonizar. Vários grupos, como a etnia Mura e a Manáos, na Amazônia, partiram para o embate mesmo em desvantagem bélica. Tal movimento serve para repensarmos que os nativos estavam longe de serem os coitadinhos ou o "índio" idealizado por José de Alencar, na estética do Romantismo, que se deixa converter e colonizar-se.

Para o processo colonizador vingar era necessário impor o ocidentalismo que tem seu nascimento delimitado a partir das novas rotas comerciais procedentes do Atlântico, com as recentes terras "descobertas".

Dessa forma, na esteira do processo de colonização, a Europa inaugurou a relação centroperiferia e, consequentemente o imaginário do mundo moderno, trazendo como resultado de tais ações os europeus como sujeitos soberanos da chamada modernidade (Mignolo, 2003).

Assim, era dever moral atribuir a cultura do colonizador ibérico aos nativos do chamado "Novo Mundo", posto que a América passava a ser encarada como uma continuidade da Europa e, portanto, não era vista em sua alteridade. Na divisão de mundo estabelecida, os dominantes fizeram questão de não perceber que havia comunidades nativas distintas e com modos de viver e fazer completamente diferenciados. Isso significa dizer que internamente, na chamada América Portuguesa, não havia apenas dois mundos, mas vários, demarcados particularmente, pela diversidade linguística. Em um artigo sobre o povo Baré, o arqueólogo Eduardo Góes Neves (2015) ressalta que:

Com uma quantidade tão grande de línguas, é esperado que os habitantes indígenas do Rio Negro sejam poliglotas, o que é a mais pura verdade; qualquer habitante da região fala com fluência pelo menos três línguas distintas: as línguas de sua mãe e de seu pai, que normalmente são diferentes porque há uma regra que prescreve o casamento entre falantes de línguas diferentes, conhecida como "exogamia linguística", bem como o português, no caso do Brasil, ou o Espanhol, no caso da Colômbia e Venezuela, línguas neolatinas que substituíram o nheengatu como língua franca (p. 48).

A exogamia linguística destacada por Neves (2015) reverbera uma prática comum entre esses diferentes mundos demarcados por etnias indígenas. Casar com falantes de línguas diferentes demonstra a construção de uma teia cultural formada por grupos diversos, mas estabelecida por laços de complementaridade que podem ser observados pela biodiversidade das plantas e frutas cultivadas em sociedades etnicamente diferentes. Isso só era possível graças às trocas que eram efetivadas pelos laços de casamentos. 
O excerto acima, bem como outros ligados aos vestígios de culturas materiais encontradas em várias partes do Brasil, serve para demonstrar que o chamado Novo Mundo, bem antes da chegada do colonizador ibérico, apresentava organizações sociais definidas, códigos de sepultamentos estabelecidos e, em alguns casos, confirmava a hierarquização social e ligação com o sobrenatural e/ou religioso. Consideramos assim, que o demonstrativo de organização do povo que habitava na América serve para preencher algumas lacunas e chamar nossa atenção para não incorrermos em determinadas armadilhas no que concerne aos estudos sobre as sociedades nativas.

A antropóloga Manuela Carneiro da Cunha (2016) afirma que uma das maiores armadilhas para os estudos sobre sociedades nativas é a ilusão do primitivismo, implantada a partir do século XIX, que criou a ideia de que algumas sociedades "teriam ficado na estaca zero da evolução, e que eram, portanto, algo como fósseis vivos que testemunhavam o passado das sociedades ocidentais" (p. 11). O primitivismo é uma das principais pegadinhas formuladas pelo pensamento eurocêntrico que permeou e ainda permeia vários discursos de que nas sociedades ágrafas não há história, só etnografia, como defendia Varnhagen.

Neste sentido, Mignolo (2003) infere que há necessidade urgente e permanente de uma geopolítica do conhecimento, visando localizar esses saberes externos, pois há um lugar de fala e esse, ao ser identificado, fica mais fácil de ouvir, como nos afirmam Nenevé e Sampaio (2015, p. 21): "os rumores externos que se impõem sobre os internos". Baseando-nos na corrente de pensamento dos autores referenciais é plausível pensar que esse seja um dos caminhos possíveis para sairmos da subalternidade do conhecimento.

Aqui, recorrendo a um poema de Manoel de Barros, Matéria de Poesia, podemos dizer que a ciência é como o rio que recebe em seu percurso todos os "trambolhos" sem perceber as margens e o que elas lhes oferecem de paus, folhas secas e de penas de urubus. A ciência também recebe tudo que o pensamento científico processa, desde as mais puras tolices até os avanços significativos para humanidade. A ciência é como as palavras para Barros, antes de chegar ao poema recebem "nossas torpezas, nossas demências, nossas vaidades". Precisamos, mais uma vez, aprender com o poeta e praticarmos uma ciência "livres das tripas do nosso espírito", caso contrário, continuaremos a percorrer o rio sem observarmos suas margens e o que elas nos ofertam.

Sem observarem a outra margem do Ocidente, colonizadores ibéricos também tentaram, e por vezes conseguiram, apagar as narrativas míticas que constituíam e definiam os territórios indígenas. Trouxeram nas bagagens inúmeras narrativas e os portugueses, especificamente, aportaram nessas terras com a "Moura Encantada" e a "Moura Torta", que tanto fazem parte do folclore lusitano quanto estão presentes nas narrativas orais contadas para crianças no Brasil, até os dias atuais.

A Moura Torta, entre os portugueses, era a escrava muito feia que, ao sair para buscar água à beira de um rio, via refletida a imagem de uma mulher bonita que estava no topo de uma árvore à espera do seu príncipe encantado. Este havia ido até seu reino para anunciar o casamento com a linda jovem. Ela, porém, só poderia aparecer para a sociedade após o anúncio do casamento e, por isso, o príncipe a deixou no topo da árvore para que ninguém a visse.

No entanto, a Moura Torta, ao pegar água em seu pote de barro, viu refletido o rosto da linda moça e não o seu e assim revoltou-se por ser tão bela e escrava. E no ápice da revolta quebrou a primeira vasilha de barro e sucessivamente as outras que lhe deram tiveram o mesmo fim, sempre alegando aos seus amos ter tropeçado e quebrado ao longo do caminho. Deramlhe, então, uma de ferro. Ao chegar à margem do rio, com a nova vasilha, viu mais uma vez $\mathrm{o}$ rosto da linda jovem refletido e, revoltou-se novamente, tentou quebrar o vasilhame de ferro. A jovem, que até então permanecera escondida e calada sobre a árvore, não resistiu e caiu na gargalhada. A Moura Torta, percebendo o engano, subiu ao topo da árvore e enfiou um alfinete 
na cabeça da Moura bonita que se tornou encantada e assumiu a forma de uma pomba. $\mathrm{O}$ príncipe ao retornar e não encontrar a amada, mas a Moura Torta, cumpriu a promessa, ainda que desolado, de casar-se com ela. Passado um tempo, uma pomba começou a aparecer no jardim do palácio para saber notícias do príncipe e, como falava, despertou o interesse do jardineiro que conseguiu capturá-la e entregá-la ao príncipe. Um dia acariciando o pequeno pássaro acabou encontrando o alfinete e, ao retirá-lo, o encanto se desfez e a amada apareceu. Ao saber do ocorrido, mandou punir a Moura Torta e foi feliz para sempre com a sua princesa.

As muitas histórias referentes às Mouras Encantadas vindas do Velho Mundo ganham nova roupagem em solos americanos. Sobre isso, Gilberto Freire em Casa Grande e Senzala assegura ao leitor que, durante o período em que os sarracenos ocuparam a Península Ibérica, as histórias da Moura Encantada foram difundidas. Quase sempre a personagem era apresentada como uma mulher de tipo exuberante, morena, de olhos pretos e de grande apelo sexual, vista pelos narradores banhando-se em águas mal-assombradas.

No Brasil, em função da visão do colonizador, a personagem que vigora é a Moura Torta, não mais representada pela escrava sarracena, mas pela mulher indígena nua, de cabelos longos, sempre vista banhando-se nos rios e gorda como as mouras. A diferença entre as duas é que as indígenas eram menos ariscas como reforça Freire (2003, p. 276) "por qualquer bugiganga ou caco de espelho estavam se entregando de pernas abertas aos caraíbas gulosos de mulher".

Podemos perceber no dizer de Freire que as táticas de modelagem utilizadas pelos portugueses em suas narrativas extraíram uma personagem já estigmatizada pela feiura e por sua condição de escrava, e que no Brasil passa a ser representada pela mulher indígena.

Caracterizar a mulher indígena como "Moura Torta" era uma forma de legitimar o falso pudor do europeu ibérico quinhentista e propagar que não existia pecado do lado de baixo do Equador e/ou que nesta outra margem tudo era permitido. Cabe-nos lembrar que, no período quinhentista, o chamado Novo Mundo era visto como um paraíso tropical e, nesse sentido, os europeus ibéricos, na condição de deuses, tudo podiam. A tática era classificar o diferente para melhor se utilizar dele. Dessa forma, o europeu ibérico apresenta os indígenas como monstros, meio homem meio demônio e preguiçosos. As mulheres são apresentadas como prostitutas e o povo como incapaz de sobreviver sem a espada do colonizador sobre suas cabeças.

Durante a fase de colonização, podemos afirmar que as narrativas inventavam, forjavam e, sobretudo, subalternizavam o Outro. Porém, é importante esclarecermos que apesar das tentativas e das narrativas que desqualificavam a condição da mulher indígena, o que o colonizador ibérico não admitia:

O fato das culturas indígenas transitarem satisfatoriamente pelas terras tropicais, obrigando o branco europeu a acatá-las em seus métodos de sobrevivência e trato com a realidade, já era um ultraje inconsciente para o cristão civilizado (Souza, 1999, p. 96).

Havia necessidade, recorrendo ao poeta Manoel de Barros, de "viver muitos anos dentro do mato" para aprender os diversos saberes com as diversas sociedades indígenas. Dominar o território não era tão fácil, por isso a necessidade de reduzir o Outro, de promover uma visão adulterada. Do "encontro" o que se estabeleceu foram duas visões cosmológicas distintas que só podiam resultar na quebra e queda do paraíso e com isso transportar os dois mordedores da maçã para os territórios das desigualdades. Com tal trajetória, esqueceram, como diz o poeta, de contrair a "moda ave", ou seja, deter o olhar de pássaro e ver as coisas por igual, mesmo que nas singularidades de cada travessia, percebendo ao longo do percurso que somos múltiplos.

Ao colocar a mulher indígena na condição de Moura Torta, o colonizador ibérico a insere numa das artimanhas do discurso colonizador ao enfatizar que o corpo colonizado deveria estar sempre pronto para servir e, nesse caso, mesmo de chacota e sexualmente. 
As mulheres amazônidas, na ótica da engenharia perversa da colonização que cada vez mais se refinava, só serviam para habitar a cama dos aventureiros que vieram para a conquista da América, pois a beleza natural e tropical, nunca foi vista nem respeitada. Portanto, há no discurso colonizador o ensejo natural de retirar ou esconder, intencionalmente, qualquer traço positivo que poderia ligar o elemento feminino à beleza, à delicadeza e à honradez. Natural então, que a imagem da Iara, a rainha encantada das águas doces, respeitada e temida pelos nativos, só apareça quando é pejorativamente mostrada como feia e gorda, como a reforçar que no novo mundo mesmo o elemento mítico, que reúne em torno de si olhares de respeito e admiração, tinha que ser combatido e anulado.

Na rota desses acontecimentos, o colonizador ibérico não percebeu que os discursos eram atravessados por outros seres, outras narrativas e por outros saberes que não se perderam com sua chegada, afinal, como ressalta Viveiro de Castro (2002), "o mundo pré-cosmológico descrito pelos mitos ameríndios é um mundo inteiramente saturado de pessoalidade ou personitude" e não se perderia facilmente.

$\mathrm{Na}$ Amazônia, assim como no resto do Brasil, a ideia de rotular a mulher indígena na condição de Moura-Torta não vingou, embora se tenha tentado de todas formas. Os nativos continuaram lutando para manter a preservação dos encantados da mata e da floresta. As Iaras, cobras grandes, sacis, curupiras, botos, juruparis, caboclinhos do mato e tantos outros continuaram a existir e a se propagar, causando medo aos invasores. Analisando o contexto, podemos afirmar que o nativo precisa ser visto na dimensão de autor e/ou produtor de seu próprio conhecimento. Para retirá-los da condição de inventado, precisamos percebê-los como inventores, pois assim o reconheceremos com a força de que precisam para que possamos vêlos como opressores e não somente como oprimidos, afinal o poder é uma via de mão dupla e se distribui e/ou se pulveriza por todos os territórios e para todos os sujeitos.

Assim, se o colonizador ibérico tinha as Mouras Encantadas e Tortas e suas variadas versões, as sociedades nativas tinham a Iara. As Iaras são seres encantados que representam as sereias das águas amazônicas por serem metade mulher e metade peixe. Iara é bonita, tem cabelos longos e pretos e tem por morada o fundo dos rios e somente vem à superfície com o pretexto de pentear os longos cabelos com um pente de ouro.

O imaginário ao apresentar a Iara com um pente de ouro no cabelo, nos leva a inferir que os colonizadores entendiam que o ser encantado sugeria e apontava com a possibilidade do Eldorado, desejado tão ardentemente pelos colonizadores, o que na realidade é uma armadilha, pois a sua intenção era a de atrair homens que se encantavam pelo metal e por sua beleza e os que se rendiam recebiam como morada o fundo dos rios. Tornavam-se assim encantados e escravos da rainha das águas doces amazônicas.

Destarte, aqui se verifica que as condições de produção desse mito dão conta de atrair o colonizador ibérico pelo que ele buscava intensamente, ou seja, o ouro. A sereia era bonita e cantava maviosamente, porém a sedução não viria pela canto da Iara, pois tal como Ulisses se precavera com cera nos ouvidos, os colonizadores firmaram o sentido da visão, porque o que atraia aqueles que chegavam era o metal dourado e irradiante que ela tinha nas mãos. Afinal, ao colonizador ibérico o que importava era conquistar e adquirir riquezas, não estavam interessados em conhecer o particular, posto que até ali se consideravam pertencentes à Europa e donos de uma cultura universal (Novaes, 1999).

Em convivência ou a partir da convivência com os povos naturais da Amazônia e com suas narrativas, os europeus ibéricos demonstraram dois sentimentos presentes na saga da colonização: cobiça e medo. O primeiro, a cobiça, reforçava o projeto colonizador, que era retirar dos primeiros habitantes o uso de suas línguas, suas crenças, desumanizar, escravizar, subalternizar, principalmente as mulheres, e acima de tudo, encontrar novos territórios/colônias e deles retirar tudo que houvesse de precioso. O segundo, o medo, foi gerado pelo desconhecido, 
afinal fincar a colonização significava vencer as desconhecidas fronteiras, os mitos, os rios, florestas, doenças e principalmente os indígenas que resistiram naquele momento.

O colonizador dominou o nativo por meios brutais, mas nunca venceu a matéria da poesia dos povos que viviam nas paragens do novo mundo: a resistência.

\section{REFERÊNCIAS}

BARROS, Manuel. Matéria de Poesia. In: Poesia completa. São Paulo: Leya, 2010 BOSI, Alfredo. Dialética da Colonização. São Paulo: Companhia das Letras, 1992. CUNHA, Manuela Carneiro. Cultura com aspas. São Paulo: Ubu Editora, 2016. DUSSEL, Enrique. 1492: O Encobrimento do Outro: A Origem do Mito da Modernidade. São Paulo: Vozes, 1993.

FANON, Frantz. Pele negra, máscaras brancas. Trad. Renato da Silveira. Salvador: EDUFBA, 2008.

FREYRE, Gilberto. Casa Grande \& Senzala. São Paulo: Global, 2003.

GIUCCI, Guillermo. Sem Fé, Lei ou Rei - Brasil 1500 - 1532. Rio de Janeiro: Rocco, 1993.

MEMMI, Albert. O Retrato do Colonizado precedido pelo Retrato do Colonizador. Rio de Janeiro: Paz e Terra, 1977.

MIGNOLLO, Walter de. Histórias Locais/Projetos Globais: colonialidade, saberes subalternos e pensamento limiar. Belo Horizonte: UFMG, 2003.

NENEVÉ, Miguel; SAMPAIO, Sonia Maria Gomes. Re-imaginar a Amazônia, Descolonizar a Escrita sobre a Região. In: ALBUQUERQUE, Gerson Rodrigues de; NENEVÉ, Miguel; SAMPAIO, Sonia Maria Gomes (Orgs). Literaturas e Amazônias: colonização e descolonização. Rio Branco: NEPAN, 2015.

NOVAES, Adauto. A Outra Margem do Ocidente. São Paulo: Companhia das Letras, 1999.

QUIJANO, Aníbal. Colonialidade do Poder e Classificação Social. In: SANTOS, Boaventura de Sousa; MENESES, Maria Paula (Orgs). Epistemologia do Sul. São Paulo: Cortez, 2010.

SOUSA, Márcio. Teatro sem Palavras. In: NOVAES, Adauto. A Outra Margem do Ocidente. São Paulo: Companhia das Letras, 1999.

VIVEIROS DE CASTRO, Eduardo. Mana vol. $8 n^{\circ}$ 01. Rio de Janeiro: Apr. 2002.

\section{Declaração de autoria e responsabilidade pelo conteúdo publicado}

Declaramos que todas as autoras tiveram acesso ao corpus de pesquisa, participaram ativamente da discussão dos resultados e revisaram e aprovaram a versão final do artigo.

Mara Genecy Centeno Nogueira, docente da UNIR, é coautora de Linguagens e Identidades da/na Amazônia Sul-Ocidental (Nepen, 2018), entre outros livros, capítulos e artigos.

Sonia Maria G. Sampaio, docente da UNIR, é coautora de Pós-Colonialismos: uma leitura política dos textos literários (Scienza, 2016), entre outros livros, capítulos e artigos.

Submetido em 03/11/2019

Aceito em 18/12/2019

Rev. Bras. Lit. Comp. Niterói, v. 22, n. 39, pp. 77-84, jan. /abr. 2020 